\title{
Physicochemical characterization of modified multicomponent binder mortar in relation to calcium hydroxide leaching
}

\author{
N. Mohamed Sutan ${ }^{1}$, I. Yakub ${ }^{1}$, S. Hamdan ${ }^{1} \&$ Z. A. Talib ${ }^{2}$ \\ ${ }^{I}$ Department of Civil Engineering, Department of Chemical Engineering \\ and Energy Sustainability and Department of Mechanical Engineering, \\ Faculty of Engineering, Univerisiti Malaysia Sarawak, Malaysia \\ ${ }^{2}$ Faculty of Science, Univeristi Putra Malaysia
}

\begin{abstract}
This paper presents and discusses the results of the study on the effects of modified multicomponent binder mortar $(\mathrm{MMCB})$ on calcium hydroxide $(\mathrm{CH})$ leaching to form calcium carbonate $\left(\mathrm{CaCO}_{3}\right)$ on the surface of cement based products, investigated in laboratory environment at daily room temperature $(\mathrm{T})$ and relative humidity (RH) in the range of $18-28^{\circ} \mathrm{C}$ and $65-90 \%$, respectively. Pozzolans used as cement replacement were Fly Ash Class F (FA) and Silica Fume (SF). Polymers used as a cement additive were styrene butadiene rubber (SBR) (Synthomer Grade 29Y46) and styrene acrylic ester (SAE) (Revacryl Grade 477). The influence of these materials on mortar has been discussed by researchers separately but their combinative influence on $\mathrm{CH}$ leachate has not been researched yet. $\mathrm{CH}$ leachate intensities in terms of percentages of $\left(\mathrm{CaCO}_{3}\right)$ resulted from Puddle Test (PT) and Standard Chemical Method (SCM) were compared systematically between MMCB samples with unmodified control mortar $(\mathrm{UCM})$ of $0.4 \mathrm{w} / \mathrm{c}$ in order to get a better understanding of how the combination of pozzolan and polymer influence $\mathrm{CH}$ leaching. The findings were discussed and substantiated physically and mechanically with the initial surface absorption test (ISAT) and compressive strength test results and micro structurally with the characterization and morphology of calcium hydroxide $(\mathrm{CH})$ and calcium silicate hydrate (C-S-H) from EDS and SEM images. The results showed that $\mathrm{MMCB}$ had less formation of $\mathrm{CaCO}_{3}$ (calcite) compared to UCM with validation from the physicochemical and mechanical analysis that
\end{abstract}


indicated the evidence of microstructural enhancement that can potentially improve concrete durability and sustainability.

Keywords: modified multicomponent binder, mortar, CH, ISAT, SEM, EDS.

\section{Introduction}

Sustainability of a material does not concern only on its economy and energy but also on its longevity and durability [1]. In recent decade sustainability as a key issue is greatly raised in the construction industry globally where the main concerns are the durability of cement based products as concrete elements that have to serve throughout their lifespans, the more efficient use of waste materials as cement replacements to reduce the energy demand of recycling, waste management and cement production and utilizing new materials. Focusing on the durability aspects of sustainability, one of indirect indication of durability problems of cement based products is calcium hydroxide $(\mathrm{CH})$ leaching that can be originated from two processes: dissolution and hydration [2-11]. $\mathrm{CH}$ leaching originated from hydration process produced calcium carbonate $\left(\mathrm{CaCO}_{3}\right)$ or calcite precipitates on cement based product as unsightly white deposit [2-9]. Both types of $\mathrm{CH}$ leaching clearly implies microstructural problem in terms of high permeability, porosity and absorption resulting in a product that is vulnerable to chemical attack and detrimental to its durability. It has been established that $\mathrm{CH}$ leaching requires the presence of $\mathrm{CH}$, water forming soluble $\mathrm{CH}$ and passages allowing the $\mathrm{CH}$ solution to migrate to the surface of samples. In other words, calcite manifestation will not occur if just one of these components is eliminated therefore hypothetically the best approach is to minimize all three.

Previous studies have shown that durability properties of cement based products can be improved by incorporating mineral admixtures or pozzolanic cementitious materials and chemical admixtures as partial cement replacements or additives through microstructural improvement in terms of producing more $\mathrm{C}$ $\mathrm{S}-\mathrm{H}$ gels that make the product impermeable. The two possibilities are by pozzolanic cement systems $[4,8]$ and polymeric cement systems [12-16] that immobilize $\mathrm{CH}$ through chemical and physical means respectively. Hypothetically, a combination of pozzolanic and polymeric systems may be the most effective. To date, there has been no attempt to study the relationship between microstructural changes within cement based materials modified with both pozzolan and polymer (MMCB) with the intensity of calcite due to $\mathrm{CH}$ leaching. Modified multicomponent binder (MMCB) systems are therefore proposed to immobilize and minimize $\mathrm{CH}$ by physical and/or chemical means which can effectively mitigate calcite manifestation.

\section{Materials and methods}

Pozzolanic cement replacements and polymeric chemical admixtures used as MMCB in this study were: Fly Ash Class F (FA), Silica Fume (SF) and Styrene Butadiene Rubber (SBR) (Synthomer Grade 29Y46), Styrene Acrylic Ester 
(SAE) (Revacryl Grade 477) from Synthomer, respectively. Their physical, chemical and mineralogical characteristics are shown in Tables 1 and 2. Ordinary Portland Cement (OPC) (ASTM Type 1 recognized by ASTM C150) manufactured by Cahaya Mata Sarawak Cement Sdn. Bhd (CMS) and it exceeds the quality requirements specified in the Malaysian Standard MS 522: Part 1: 1989 Specifications for Ordinary Portland Cement. The raw materials are clinker $(90 \%)$, limestone $(5 \%)$, and gypsum $(5 \%)$.

Table 1: $\quad$ Physical and chemical properties of SBR and SAE [2].

\begin{tabular}{|c|l|}
\hline Polymer additives & \multicolumn{1}{|c|}{ Physical and chemical properties } \\
\hline $\begin{array}{c}\text { Styrene Butadiene } \\
\text { Rubber (SBR) } \\
\text { (Synthomer Grade }\end{array}$ & $\begin{array}{l}\text { Physical form: liquid: colour: white; vapour } \\
\text { pressure: } 23 \mathrm{hPa}\left(\text { at } 20^{\circ} \mathrm{C}\right) \text {; relative density: } 0.9-1.1 \\
\text { Composition: carboxylated styrene butadiene } \\
\text { 29Y46) }\end{array}$ \\
$\begin{array}{c}\text { CSB) } \\
\text { Stabilizers: surfactant; total solids }(\%): 47 \\
\text { Typical viscosity }(\mathrm{mPas}): 90 ; \mathrm{pH}: 10 ; \text { Min. film } \\
\text { forming temperature }\left({ }^{\circ} \mathrm{C}\right): 0 ; \mathrm{Tg}\left({ }^{\circ} \mathrm{C}\right): \text { Onset }=-17 \\
\text { Midpoint }=-8 ; \text { particle size }(\mu \mathrm{m})=0.2\end{array}$ \\
\hline $\begin{array}{c}\text { Styrene Acrylic Ester } \\
\text { (SAE) }\end{array}$ & $\begin{array}{l}\text { Physical form: liquid; colour: white; composition: } \\
\text { styrene acrylic; stabilizers: surfactant; total solids } \\
(\%): 57 ; \text { typical viscosity }(\mathrm{mPas}): 1850 ; \mathrm{pH}: 8 ;\end{array}$ \\
& $\begin{array}{l}\text { Min. film forming temperature }\left({ }^{\circ} \mathrm{C}\right): 23 ; \mathrm{Tg}\left({ }^{\circ} \mathrm{C}\right): \\
\text { Onset }=13 \text { midpoint }=18 ; \text { particle size }(\mu \mathrm{m})=0.2\end{array}$ \\
\hline
\end{tabular}

To study the combinative effect of MMCB in cement to $\mathrm{CH}$ leachate in terms of percentages of calcite $\left(\% \mathrm{CaCO}_{3}\right)$ obtained from Puddle Test (PT) and Standard Chemical Method (SCM),comparison were made between \%calcite on 4 MMCB mortar samples and unmodified control mortar (UCM) of $0.4 \mathrm{w} / \mathrm{c}$ and the findings were linked, discussed and substantiated micro structurally by focusing on combinative polymer-pozzolan-cement interaction using the morphology and characterization analysis of calcium hydroxide $(\mathrm{CH})$ and calcium silicate hydrate (C-S-H) obtained from Scanning Electron Microscope (SEM) and Energy Dispersive X-ray Spectroscopy (EDS) results, physically by initial surface absorption test (ISAT) and mechanically by compressive strength test $(\mathrm{CS})$ results. 10\% pozzolan modified mortar (PMM) and 10\% polymer composite mortar (PCM) were used in this study. The mix proportion was set at (cement: sand: water) 1:1.67:0.4(w/c) for all specimens that were casted into Universal Containers $30 \mathrm{ml}$ (28 mm diameter, $85 \mathrm{~mm}$ height) for PT and $150 \mathrm{~mm}$ X $150 \mathrm{~mm}$ X $150 \mathrm{~mm}$ cubes for ISAT and CS tests. All specimens were aircured in the concrete laboratory at Universiti Malaysia Sarawak at daily room temperature (T) and relative humidity $(\mathrm{RH})$ in the range of $18-28^{\circ} \mathrm{C}$ and $65-$ 90\%, respectively. PT and SCM were performed from day 7, 14, 21 and 28. Meanwhile CS was performed from day 7, 21 and 28. ISAT was performed on 
day 28. Polished small samples were prepared and analysed using SEM/EDS at day 28. Acetone was used to discontinue the hydration process of these samples. SEM/EDS images and spectrum for all prepared samples were captured by a Scanning Electron Microscope and Energy Dispersive X-ray Spectroscopy (JSM-6701F) supplied by JEOL Company Limited, Japan that followed the ASTM C 1723-10 (2010) code of practice.

Table 2: Chemical composition of OPC, FA and SF.

\begin{tabular}{|c|c|c|c|c|}
\hline Composition (\%) & $\mathrm{CaO}$ & $\mathrm{SiO}_{2}$ & $\mathrm{Al}_{2} \mathrm{O}_{3}$ & $\mathrm{Fe}_{2} \mathrm{O}_{3}$ \\
\hline OPC & 63.0 & 21.79 & 5.75 & 3.25 \\
\hline Fly Ash Class F & 5.0 & 52 & 23 & $<1$ \\
\hline Silica Fume & $<1$ & 85 to 97 & & \\
\hline
\end{tabular}

\section{Results and discussion}

\subsection{The effects of MMCB on intensity of calcite}

Figure 1 and Table 3 show the comparisons of the percentage of calcite collected from the surfaces of modified multicomponent binder mortar (MMCB) samples of $0.4 \mathrm{w} / \mathrm{c}$ ratio and the unmodified control mortar (UCM) sample of 7, 14, 21, 28,60 and 90 days.

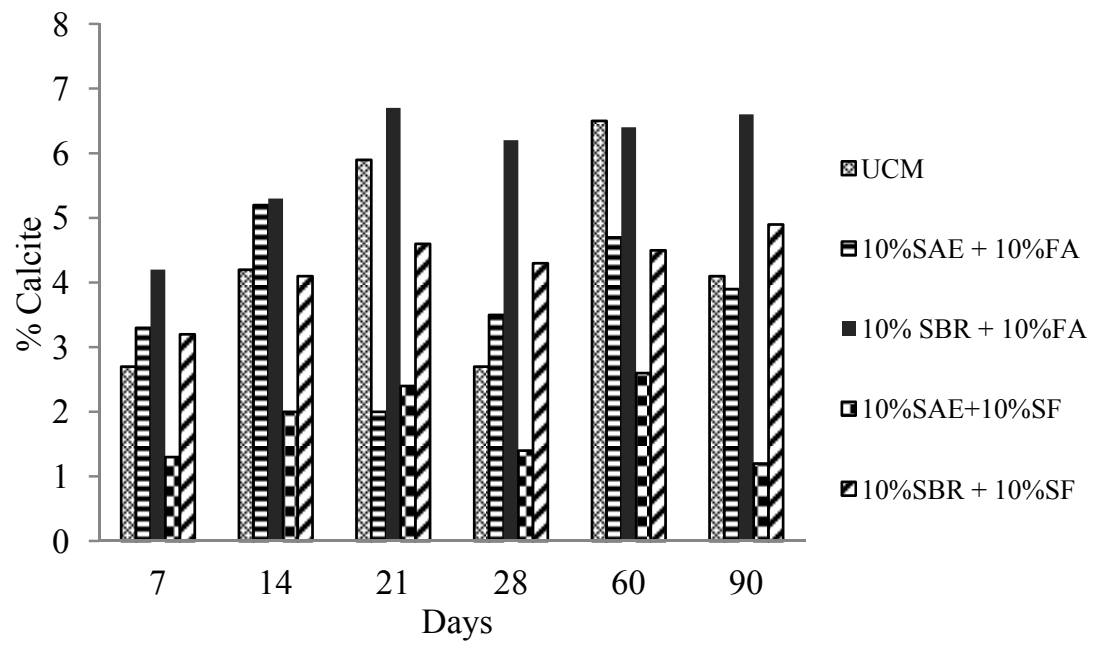

Figure 1: Calcite intensity on MMCB mortar surfaces compare to UCM. 
Table 3: Calcite intensity on MMCB mortar surfaces of $0.4 \mathrm{w} / \mathrm{c}$.

\begin{tabular}{|l|c|c|}
\hline & Total calcite intensity & $\%$ Calcite reduction \\
\hline $10 \% \mathrm{SBR}+10 \% \mathrm{SF}$ & 25.6 & $1.9 \%$ \\
\hline $10 \% \mathrm{SAE}+10 \% \mathrm{SF}$ & 10.9 & $58.2 \%$ \\
\hline $10 \% \mathrm{SBR}+10 \% \mathrm{FA}$ & 35.4 & $35.6 \%$ (increase) \\
\hline $10 \% \mathrm{SAE}+10 \% \mathrm{FA}$ & 22.6 & $13.4 \%$ \\
\hline $\mathrm{UCM}$ & 26.1 & \\
\hline
\end{tabular}

Figure 2 and Table 4 show the comparisons of the percentage of calcite collected from the surfaces of $10 \% \mathrm{SAE}+10 \% \mathrm{SF}$ mortar sample in comparison with $10 \% \mathrm{SF}, 10 \% \mathrm{SAE}$ and $\mathrm{UCM}$ sample for $7,14,21,28,60$ and 90 days.

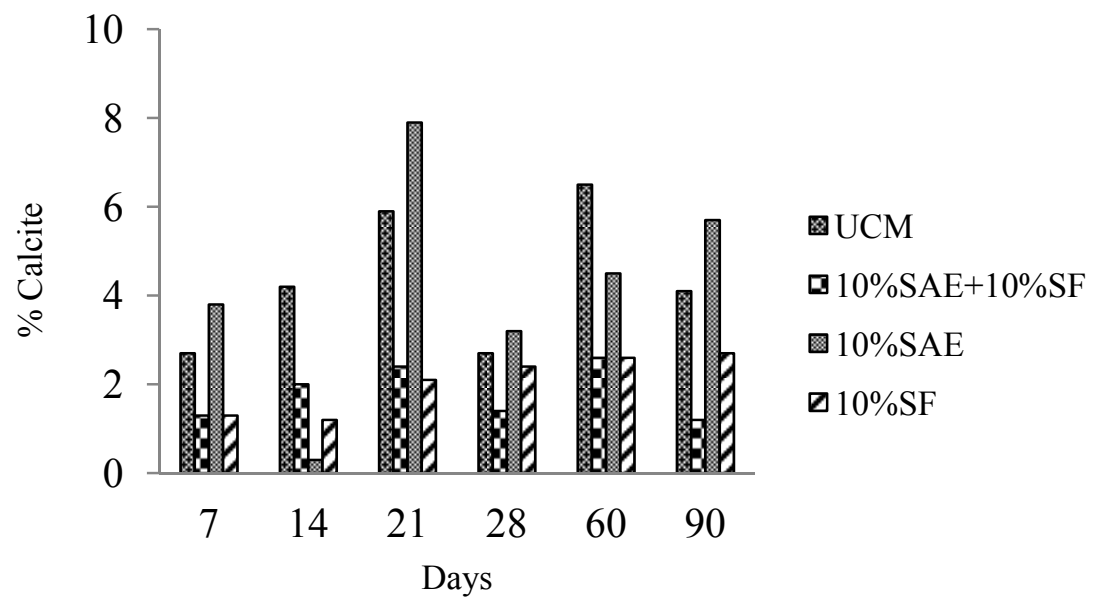

Figure 2: Calcite intensity on MMCB, PMM and PCM surfaces compared to UCM.

Table 4: Calcite intensity for $0.4 \mathrm{w} / \mathrm{c}$.

\begin{tabular}{|c|c|c|}
\hline & Total calcite intensity & \% Calcite reduction \\
\hline $10 \% \mathrm{SF}$ & 12.3 & $52.9 \%$ \\
\hline $10 \% \mathrm{SAE}$ & 25.5 & $2.3 \%$ \\
\hline $10 \% \mathrm{SAE}+10 \% \mathrm{SF}$ & 10.9 & $58.2 \%$ \\
\hline UCM & 26.1 & \\
\hline
\end{tabular}


Figure 1 shows MMCB mortar manifests significantly lower \%calcite in comparison with $\mathrm{UCM}$ specifically $10 \% \mathrm{SAE}+10 \% \mathrm{SF}$ which reduced $\mathrm{CH}$ leachate up to $58.2 \%$ in comparison with $\mathrm{UCM}(\% \mathrm{EI}$ reduction $=(($ Total EI $-\mathrm{EI}$ $\mathrm{UCM} / \mathrm{UCM}$ EI) $\times 100$ ). Besides, $10 \% \mathrm{SAE}+10 \% \mathrm{SF}$ manifested the least $\mathrm{CH}$ leachate compared to calcite intensities of $10 \% \mathrm{SF}$ and $10 \% \mathrm{SAE}$ (shown in Figure 2 and Table 4), proving the hypothesis of this study that combinative effects of pozzolan and polymer in terms of reduction of $\mathrm{CH}$ and pathway to leach can significantly reduce $\mathrm{CH}$ leachate. The next section will further justify, substantiate and discuss the result in terms of physicochemical behaviour by focusing on combinative polymer-pozzolan-cement interaction by using the morphology of $\mathrm{CH}$ and C-S-H from the SEM result, physically by initial surface absorption test (ISAT), and mechanically by compressive strength test (CS) results.

\subsection{Pozzolan-polymer interaction evidence by the morphology of $\mathrm{CH}$ and C-S-H of MMCB mortar: SEM and EDS}

Morphology of $\mathrm{CH}$ and C-S-H can be seen through SEM images of samples. Figure 3 shows the SEM images of UCM and MMCB mortar samples at 28 days.

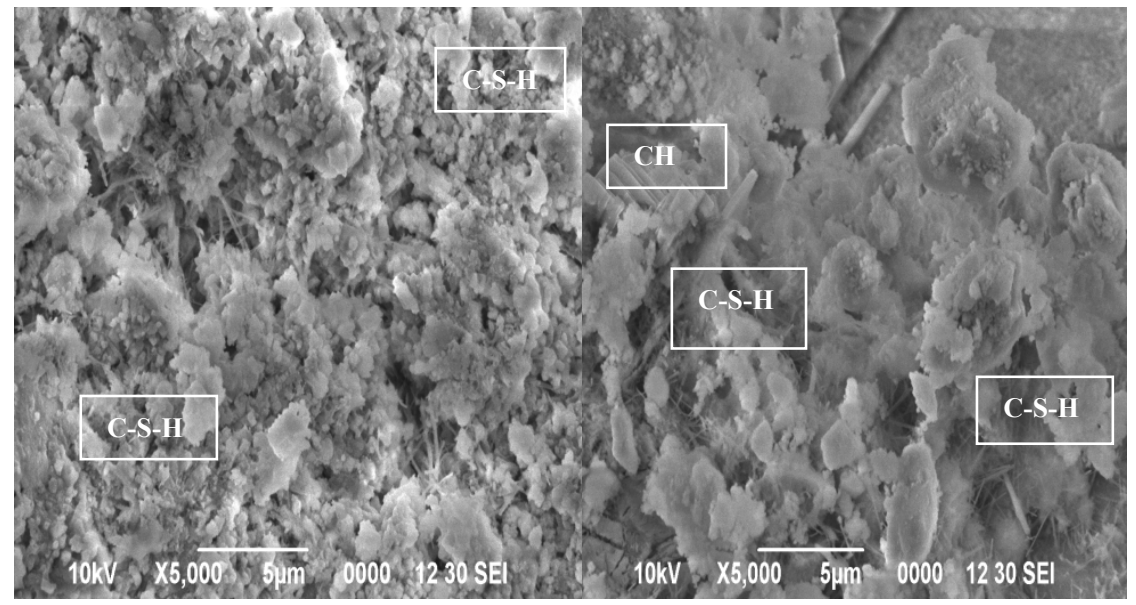

(a)

(b)

Figure 3: Morphological observation from SEM images of (a) UCM and (b) $10 \% \mathrm{SAE}+10 \% \mathrm{SF}$ samples at day 28 .

The SEM image of MMCB in figure 3(b) clearly shows a mixture of $\mathrm{CH}$ and $\mathrm{SAE}$ which is the evidence of the interaction of solid particles of the carboxylate group of SAE with the free valences of calcium atoms on the surface of $\mathrm{CH}$ solid plate-like morphology [17]. Furthermore, evidence of pozzolanic interaction between $\mathrm{CH}$ and SF producing $\mathrm{C}-\mathrm{S}-\mathrm{H}$ can be observed by abundant presence of $\mathrm{C}-\mathrm{S}-\mathrm{H}$ flowery-like morphology [18]. These observations substantiate the $\mathrm{CH}$ leachate results. 
Energy Dispersive X-ray Spectroscopy (EDS) characterization technique is used to further substantiate the results and findings from $\mathrm{CH}$ leachate test by using $\mathrm{Ca} / \mathrm{Si}$ ratio obtained from EDS spectra for $\mathrm{CH}$ and $\mathrm{C}-\mathrm{S}-\mathrm{H}$ characterization. The $\mathrm{Si} / \mathrm{Ca}$ ratios are somewhat varies but approximately between 0.45 to 0.50 in hydrated Portland cement but up to about 0.6 if fly ash or silica fume are present and depending on the proportions. $\mathrm{CH}$ is formed mainly from alite hydration having $\mathrm{Ca} / \mathrm{Si}$ ratio of 3 and $\mathrm{C}-\mathrm{S}-\mathrm{H}$ has a $\mathrm{Ca} / \mathrm{Si}$ ratio of approximately 2 . The $\mathrm{Ca} / \mathrm{Si}$ ratio of $\mathrm{C}-\mathrm{S}-\mathrm{H}$ in Figure 4(a) and (b) samples can be calculated as 2 and 1.58, respectively. The $\mathrm{Si} / \mathrm{Ca}$ ratio of $\mathrm{CH}$ in Figure 4(a) and (b) samples can be calculated as 0.50 and 0.63 respectively. The result of $10 \% \mathrm{SAE}+10 \% \mathrm{SF}$ clearly show the evidence of less $\mathrm{C}-\mathrm{S}-\mathrm{H}$ and less $\mathrm{CH}$ for $10 \% \mathrm{SAE}$ and $10 \% \mathrm{SF}$ due interaction between $\mathrm{CH}$ and $\mathrm{SAE}$ and $\mathrm{SF}$ to which corroborate leachate and morphological results in previous sections.

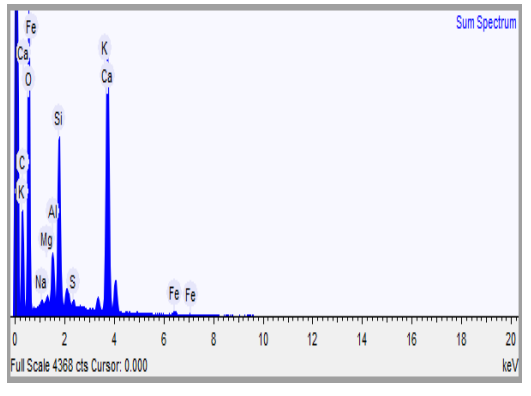

(a) $0.4 \mathrm{w} / \mathrm{c}(\mathrm{Ca} / \mathrm{Si}=2.0)$

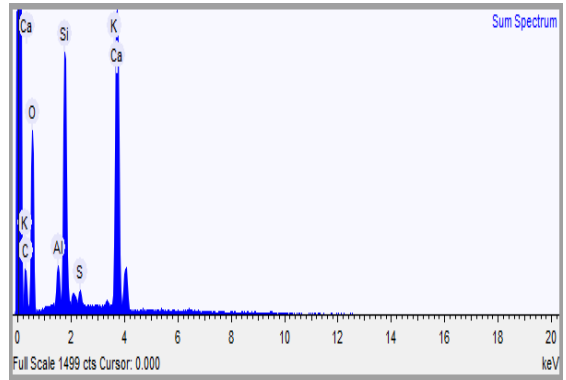

(b) $10 \% \mathrm{SAE}+10 \% \mathrm{SF}(\mathrm{Ca} / \mathrm{Si}=1.58)$

Figure 4: FEDS pattern of (a) UCM and (b) $10 \% \mathrm{SAE}+10 \% \mathrm{SF}$ at day 28 .

\subsection{The combination effect of Pozzolan-polymer reaction on physical and mechanical properties of MMCB mortar in relation to $\mathrm{CH}$ leachate: initial surface absorption test and compressive strength tests}

Figures 5 and 6 show the initial surface absorption rate and compressive strength recorded for 3 different samples in comparison with UCM sample. $10 \% \mathrm{SAE}+10 \% \mathrm{SF}$ sample showed obvious advantage in terms of initial surface water absorption rate and compressive strength compare to $10 \% \mathrm{SF}, 10 \% \mathrm{SAE}$ and UCM samples. Similarly, the highest strength achieved by $10 \% \mathrm{SAE}+10 \% \mathrm{SF}$ sample is of $24.5 \mathrm{MPa}$ at day 28 which is $20 \%$ improvement from UCM. The results show that the highest strength of MMCB can be achieved by the combination of pozzolanic effect of SF and the water-reducing and filling effect of SAE. Lower absorption can give cement mortars such properties as higher compressive strength, higher micro hardness value in interfacial zone and lower effective diffusion coefficient of $\mathrm{Ca}^{2+}$ ion in matrix .This is obvious since the least reduction of leachate of $10 \% \mathrm{SAE}+10 \% \mathrm{SF}$ is also partly due to the excellent microstructure produced by the interaction of both SAE and SF with $\mathrm{CH}$ producing abundant $\mathrm{C}-\mathrm{S}-\mathrm{H}$ that produce least path for $\mathrm{CH}$ to leach $[16,17]$. 


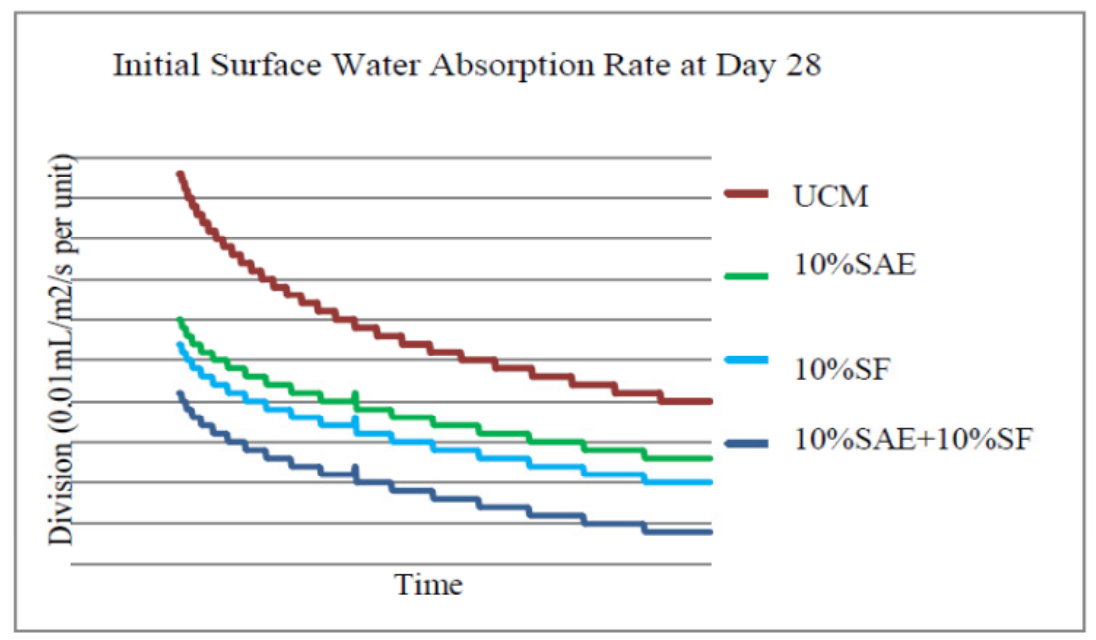

Figure 5: Comparison of initial surface absorption rate at day 28.

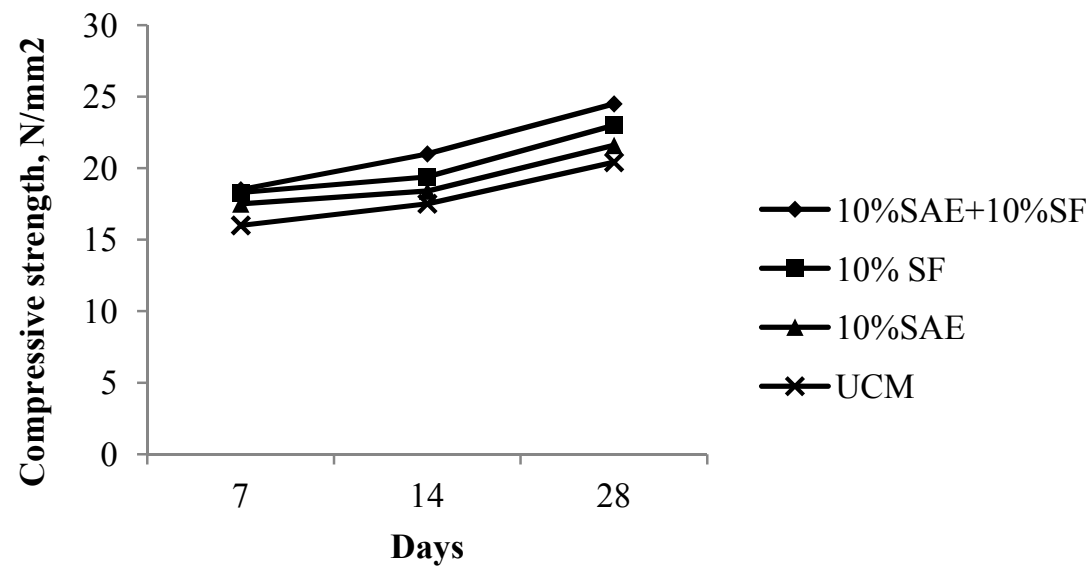

Figure 6: Comparison of strength development of MMCB samples with UCM, PMM and PCM samples.

\section{Conclusions}

1. MMCB mortar manifests significantly lower calcite in comparison with UCM specifically $10 \% \mathrm{SAE}+10 \% \mathrm{SF}$ reduced leachate up to $58.2 \%$ in comparison with UCM. 
2. $10 \% \mathrm{SAE}+10 \% \mathrm{SF}$ manifested the least calcite in comparison with $10 \% \mathrm{SF}$ and $10 \% \mathrm{SAE}$ proving the hypothesis of this study that combinative effects of pozzolan and polymer in terms of reduction of $\mathrm{CH}$ and pathway to leaching can significantly reduce $\mathrm{CH}$ leachate.

3. The physical and mechanical properties in terms of in initial surface absorption and compressive strength of UCM were extensively improved with the combination of $10 \% \mathrm{SAE}$ and $10 \% \mathrm{SF}$ by reduction of absorption and $31 \%$ of strength increased respectively that evidently substantiate the calcite intensity and morphology results.

4. MMCB has the potential of improving the durability and in effect sustainability of cement based products.

\section{Acknowledgements}

The research work reported in this paper has been funded by the Ministry of Education Malaysia under the projects FRGS/03(04)/772/2010(53) and ERGS/TK04(02)/1011/2013(08).

\section{References}

[1] Neville, A., Concrete: Neville's insights and issues. Thomas Telford pg. 5, 2006.

[2] Kresse, P., Efflorescence-Mechanism of Occurrence and Possibilities of Prevention. Betonwerk+Fertigteil-Technik, (53), pp. 160-168, 1987.

[3] Kresse, P., Efflorescence and its prevention. Betonwerk+FertigteilTechnik, (57), pp. 84-88, 1991.

[4] Higgins, D.D., Appearance Matters, No. 4.: Cement and Concrete Association, 1982.

[5] Neville, A., Efflorescence-surface blemish of internal problem? Part 2: Situation in practice. Concrete International, (10), 2002.

[6] Neville, A., Efflorescence-surface blemish of internal problem? Part 1: The knowledge. Concrete International, (24), 2002.

[7] Bensted, J., Efflorescence-prevention is better than cure. Concrete, (24), pp. 40-41, 2000.

[8] Kresse, P., Coloured concrete and its enemy: efflorescence. Chemistry and Industry, pp. 93-95, 1989.

[9] Dow, C. \& Glassier F.P., Calcium carbonate efflorescence on Portland cement and building materials. Cement and Concrete Research, (33), pp. 147-154, 2003.

[10] Marchand, J, Bentz, D.P., Samson, E., Maltais, Y., Influence of Calcium Hydroxide Dissolution on the Transport Properties of Hydrated Cement Systems. Materials Science of Concrete: Calcium Hydroxide in Concrete, Special Volume, Proceedings. American Ceramic Society, pp. 113-129, 2001. 
[11] Gaitero, J.J., Campillo, I., Guerrero, A., Reduction of the calcium leaching rate of cement paste by addition of silica nanoparticles. Cement and Concrete Research, (38) pp. 8-9, 2008.

[12] Ohama, Y., Recent Progress in Concrete-Polymer Composites. Advance Cement Based Materials, (5), pp. 31-40, 1997.

[13] Ohama, Y., Polymer-based Admixtures. Cement and Concrete Composites, (20), pp. 189-212, 1998.

[14] Kardon, J.B., Polymer-Modified Concrete: Review. Journal of Materials in Civil Engineering, pp. 85-92,1997

[15] Soufiane Benosman, A., Mouli, M., Taibi, H., Belbachir, M., Senhadji, Y., Behlouli, I. \& D, Houivet, D., Mineralogical Study of Polymer-Mortar Composites with PET Polymer by Means of Spectroscopic Analyses. Material Sciences and Applications, (3), pp. 139-150, 2012.

[16] Gomes, C.E.M. \& Ferreira, O.P., Analysis of Microstructural Properties of VA/VEAVA Coplymer Modified Cement Pastes. Polimeros: Ciencia e Tecnologia, (5), pp. 193-198, 2005.

[17] Chandra, S. and Ohama, Y., Polymers in Concrete, CRC Press, USA, pp. 163, 1994.

[18] Malhotra, V.M. \& Mehta, P.K. (2004) Pozzolanic and Cementitious Materials. Taylor \& Francis, London. 